\title{
Reaction Kinetics of the CN Radical with Methyl Bromide
}

\author{
Michael Hodny and John F. Hershberger \\ Department of Chemistry and Biochemistry, Dept. 2735, PO Box 6050, \\ North Dakota State University, Fargo, ND 58108-6050
}

\begin{abstract}
The kinetics of the $\mathrm{CN}+\mathrm{CH}_{3} \mathrm{Br}$ reaction were studied using transient infrared laser absorption spectroscopy to detect $\mathrm{CN}$ reactants and $\mathrm{HCN}$ products. This reaction has a rate constant of $\mathrm{k}=$ $(2.20 \pm 0.6) \times 10^{-12} \exp (453 \pm 98 / \mathrm{T}) \mathrm{cm}^{3}$ molecule $\mathrm{c}^{-1} \mathrm{~s}^{-1}$ over the range 298-523 K. Hydrogen abstraction to produce $\mathrm{HCN}+\mathrm{CH}_{2} \mathrm{Br}$ is only a minor reaction product, with a branching fraction of 0.12 \pm 0.02 . Other product channels, including $\mathrm{BrCN}+\mathrm{CH}_{3}, \mathrm{CH}_{2} \mathrm{CN}+\mathrm{HBr}, \mathrm{CH}_{3} \mathrm{CN}+\mathrm{Br}$ are likely. An upper limit of 0.01 was established for the $\mathrm{HBr}$ yield. These results are in qualitative agreement with recent ab initio calculations.
\end{abstract}

Corresponding author. Email: john.hershberger@ndsu.edu. FAX (701)-231-8831

(C) 2015. This manuscript version is made available under the Elsevier user license http://www.elsevier.com/open-access/userlicense/1.0/ 


\section{Introduction}

The kinetics of the $\mathrm{CN}$ radical are of interest due to the role of this molecule in combustion chemistry and atmospheric chemistry. Previous kinetic studies of $\mathrm{CN}$ reactions include measurements with a variety of molecules such as saturated and unsaturated hydrocarbons [1-13], $\mathrm{O}_{2}$ [1,14-22], $\mathrm{NO}$ [21,23], and $\mathrm{NO}_{2}$ [22,23]. Past work in our laboratory has included study of $\mathrm{CN}$ reactions with $\mathrm{O}_{2}$ [24,25], $\mathrm{NO}_{2}$ [26], OCS [27], $\mathrm{CS}_{2}$ [28], $\mathrm{SO}_{2}$ [28], HCNO [29,30], small primary alcohols [31], and chlorinated methanes including $\mathrm{CH}_{3} \mathrm{Cl}$ [32]. To date, however, there is no experimental literature on the kinetics of $\mathrm{CN}$ reactions with $\mathrm{CH}_{3} \mathrm{Br}$, methyl bromide. This molecule is a trace component of the atmosphere, partly due to recent use as a fumigant, and plays a role in stratospheric ozone depletion and is a greenhouse gas. There is, however, a recent ab initio study of reactions of $\mathrm{CN}$ with several halomethanes, including $\mathrm{CH}_{3} \mathrm{Cl}$ and $\mathrm{CH}_{3} \mathrm{Br}$ [33]. In that study, reaction pathways were calculated at the G4 level of theory, using B3LYP/GTBas3 and/or QCISD/GTBas3 optimized structures. The most probable reaction channels were found to be either hydrogen abstraction or halogen abstraction by the carbon atom on $\mathrm{CN}$. The lowest energy pathway for the $\mathrm{CN}+\mathrm{CH}_{3} \mathrm{Cl}$ reaction was the expected hydrogen abstraction to produce $\mathrm{HCN}+\mathrm{CH}_{2} \mathrm{Cl}$; this prediction is consistent with the experimental observation of a positive activation energy [32], typically observed for hydrogen abstraction reactions. For $\mathrm{CN}+\mathrm{CH}_{3} \mathrm{Br}$, however, the two reaction pathways were calculated to have nearly identical barrier heights: hydrogen abstraction $(4.9 \mathrm{kcal} / \mathrm{mole}$ standard Gibbs energy of activation) to produce $\mathrm{HCN}+\mathrm{CH}_{2} \mathrm{Br}$, and attack at the bromine atom $(5.0 \mathrm{kcal} / \mathrm{mole}$ standard Gibbs energy of activation) to produce $\mathrm{BrCN}+\mathrm{CH}_{3}, \mathrm{CH}_{2} \mathrm{CN}+\mathrm{HBr}$, or $\mathrm{CH}_{3} \mathrm{CN}+\mathrm{Br}$ [33]. This calculation therefore suggests the possibility that $\mathrm{HCN}$ is not necessarily the major product of this reaction. No experimental data has been previously reported on the kinetics of this reaction . The primary goal of the experimental study described here is to test that prediction. We report measurements of total rate constants and quantitative HCN product yields:

$$
\mathrm{CN}+\mathrm{CH}_{3} \mathrm{Br} \quad \rightarrow \mathrm{HCN}+\mathrm{CH}_{2} \mathrm{Br} \quad \Delta \mathrm{G}^{0}=-115.5 \mathrm{~kJ} / \mathrm{mol}
$$




$$
\begin{array}{ll}
\rightarrow \mathrm{CH}_{2} \mathrm{CN}+\mathrm{HBr} & \Delta \mathrm{G}^{0}=-182.0 \mathrm{~kJ} / \mathrm{mol} \\
\rightarrow \mathrm{CH}_{3} \mathrm{CN}+\mathrm{Br} & \Delta \mathrm{G}^{0}=-211.7 \mathrm{~kJ} / \mathrm{mol} \\
\rightarrow \mathrm{BrCN}+\mathrm{CH}_{3} &
\end{array}
$$

The thermodynamic values are obtained from the ab initio study [33]; none was reported for channel (1d).

\section{Experimental}

Cyanogen Iodide (ICN) was photolyzed by $266 \mathrm{~nm}$ light from the fourth harmonic of an Nd:YAG laser (Continuum Surelite-II):

$$
\mathrm{ICN}+h v(266 \mathrm{~nm}) \rightarrow \mathrm{CN}+\mathrm{I}
$$

$\mathrm{CN}$ radicals and $\mathrm{HCN}$ reaction products were detected by time-resolved infrared diode laser absorption spectroscopy using lead salt diode lasers (Laser Components) operating at $85-110 \mathrm{~K}$. A 5-cm $\mathrm{CaF}_{2}$ lens was used to collimate the infrared light, and this beam was combined with the UV light from the Nd:YAG laser by a dichroic mirror. Iris diaphragms were used to restrict both beams to $6 \mathrm{~mm}$ diameter, and both beams were passed through a single pass absorption cell (146 $\mathrm{cm}$ length for room temperature experiments, $143 \mathrm{~cm}$ length for elevated temperature measurements). The beams were separated by a monochromator, and the IR beam was focused onto a $1 \mathrm{~mm}$ InSb detection chip (Cincinnati Electronics, $\sim 1 \mu$ s response time). Transient signals were recorded and signal averaged on a digital oscilloscope, then stored on a computer for analysis. Rate coefficient measurements were obtained over the temperature range 298-523 K. Elevated temperatures were achieved by resistive heating, and temperatures were measured with a thermocouple. Product yield measurements were performed at $298 \mathrm{~K}$. Typical reaction conditions were $\mathrm{P}(\mathrm{ICN})=0.1$ Torr $\left(3.24 \times 10^{15}\right.$ molecule $\left.\mathrm{cm}^{-3}\right), \mathrm{P}\left(\mathrm{SF}_{6}\right)=0.5$ Torr $\left(1.62 \times 10^{16}\right.$ 
molecule $\left.\mathrm{cm}^{-3}\right)$, and $\mathrm{P}\left(\mathrm{CH}_{3} \mathrm{Br}\right)$ varied over the range $0.0-2.0$ Torr $\left(0.0-6.38 \times 10^{16}\right.$ molecule $\mathrm{cm}^{-3}$ ), resulting in total pressure of 0.6-2.6 Torr.

Typical photolysis pulse laser energies were 7-12 mJ/pulse. Based on a previously measured $266 \mathrm{~nm}$ absorption coefficient for ICN of $0.009 \mathrm{~cm}^{-1}$ Torr $^{-1}$ [34], and assuming a unity quantum yield, we estimate typical initial number densities of $[\mathrm{CN}]_{0} \sim 3 \times 10^{13}$ molecules $\mathrm{cm}^{-3}$. Only a negligible increase in temperature is caused by absorption of the UV laser pulse. $\mathrm{CH}_{3} \mathrm{Br}$ absorbs only very weakly at $266 \mathrm{~nm}$, [35] so photolytic formation and subsequent secondary chemistry of $\mathrm{CH}_{3}$ or $\mathrm{Br}$ is negligible. Data was collected using static gas fills, as the low vapor pressure of the ICN reagent makes a flow experiment difficult. Each gas fill was limited to 10-20 photolysis laser pulses in order to minimize depletion of precursor molecules or accumulation of product molecules. The $\mathrm{SF}_{6}$ was present as a nonreactive buffer gas, primarily to promote vibrational and rotational relaxation of reactant and product molecules to a Boltzmann distribution. It's effectiveness at relaxing vibrational excitation has been demonstrated in an early publication from our laboratory [36] for detection of some product molecules, but not HCN; this issue is discussed in section 3.2.

ICN (Fluka, 97\%) was purified by vacuum sublimation to remove any dissolved gasses. $\mathrm{CH}_{3} \mathrm{Br}$ (Aldrich) was purified by several freeze-pump-thaw cycles at $77 \mathrm{~K}$.

The following molecules were probed using IR diode laser absorption spectroscopy:

$$
\begin{aligned}
& \mathrm{CN}(v=1 \leftarrow v=0) \quad \mathrm{R}(10) \text { at } 2081.689 \mathrm{~cm}^{-1} \\
& \mathrm{HCN}(v=1 \leftarrow v=0) \mathrm{P}(19) \text { at } 3251.822 \mathrm{~cm}^{-1}
\end{aligned}
$$

The HITRAN database [37] as well as other published spectroscopic data [38,39] was used for locating and identifying spectral lines of $\mathrm{HCN}$. Other published sources were used to locate and identify spectral lines of $\mathrm{CN}$ [40] and $\mathrm{BrCN}$ [41].

\section{Results}




\subsection{Total rate coefficients}

The total rate coefficient of the $\mathrm{CN}+\mathrm{CH}_{3} \mathrm{Br}$ reaction was determined by direct timeresolved detection of $\mathrm{CN}$ radicals, as shown in Figure 1. The rapid rise in absorption is attributed to photolytic formation of $\mathrm{CN}$; the precursor is known to produce primarily ground vibrational state but rotationally hot $\mathrm{CN}$; this rotational excitation is quickly $(<10 \mu \mathrm{s})$ relaxed to a Boltzmann distribution under our conditions. The slower decay of the transient signal is attributed to loss of $\mathrm{CN}$; in the absence of $\mathrm{CH}_{3} \mathrm{Br}$ reagent, this loss includes diffusional loss of $\mathrm{CN}$ from the probed reaction volume as well as reaction of $\mathrm{CN}$ with trace $\mathrm{O}_{2}$ (probably the dominant contribution, as vacuum sublimation of ICN crystals removes most but not all dissolved air) and to some extent, radical-radical chemistry such as self reaction. Upon addition of $\mathrm{CH}_{3} \mathrm{Br}$, the decay rate was found to substantially increase, and was well described by a single exponential decay. Figure 2 shows the decay rate as a function of $\mathrm{CH}_{3} \mathrm{Br}$ pressure. Under our conditions, pseudofirst order kinetics, i.e. $[\mathrm{CN}]<<\left[\mathrm{CH}_{3} \mathrm{Br}\right]$ applies at $\mathrm{CH}_{3} \mathrm{Br}$ pressures above $\sim 20$ mTorr. Therefore, a standard treatment gives

$$
\begin{aligned}
& {[\mathrm{CN}]_{t}=[\mathrm{CN}]_{0} \exp \left(-\mathrm{k}^{\prime} \mathrm{t}\right)} \\
& \mathrm{k}^{\prime}=\mathrm{k}_{1}\left[\mathrm{CH}_{3} \mathrm{Br}\right]+\mathrm{k}_{0}
\end{aligned}
$$

where $\mathrm{k}^{\prime}$ is the observed pseudo-first order $\mathrm{CN}$ signal decay, $\mathrm{k}_{1}$ is the desired bimolecular rate coefficient, and $\mathrm{k}_{0}$ is the pseudo-first order decay in the absence of methyl bromide reagent (attributed to self-reaction, reaction with trace oxygen, and/or diffusional loss out of the probed beam volume). Figure 2 shows a plot of k' as a function of $\left[\mathrm{CH}_{3} \mathrm{Br}\right]$. The desired bimolecular rate coefficient $\mathrm{k}_{1}$ is obtained from the slope of this plot. 


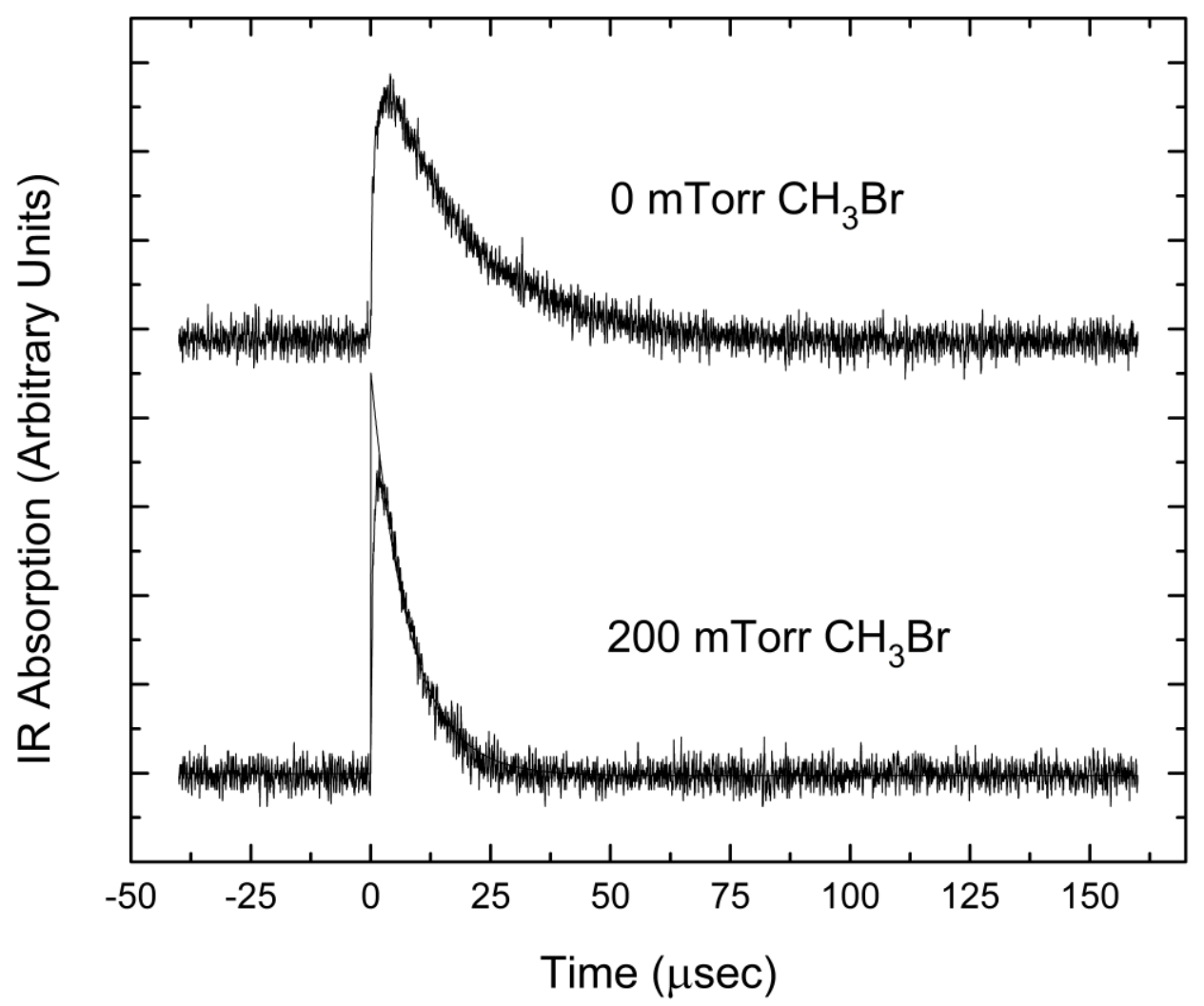

Figure 1: Infrared absorption transients, detecting [CN] vs time. Upper trace: without added reagent. Lower trace: with 0.2 Torr $\left(6.5 \times 10^{15}\right.$ molec cm$\left.^{-3}\right)$ of $\mathrm{CH}_{3} \mathrm{Br}$ reagent. Also shown on lower trace is a single exponential decay fit to the data. Other conditions (both traces): $\mathrm{P}(\mathrm{ICN})=$ 0.1 Torr, $\mathrm{P}\left(\mathrm{SF}_{6}\right)=0.5$ Torr. 


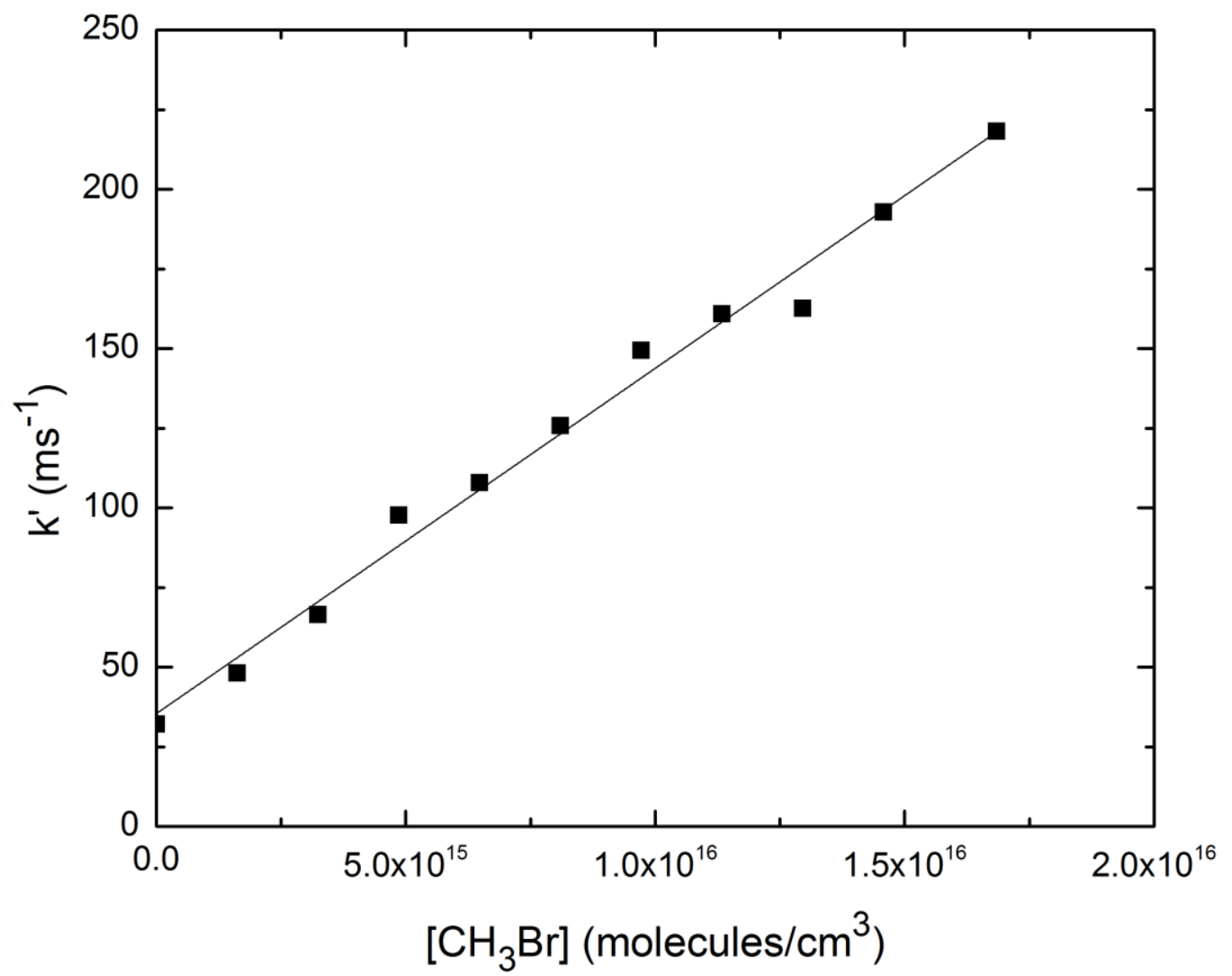

Figure 2: Plot of pseudo-first-order decay rate k' vs. $\mathrm{CH}_{3} \mathrm{Br}$ pressure. Data obtained at $298 \mathrm{~K}$.

Rate coefficients were determined over the temperature range 298-523 K. Figure 3 shows an Arrhenius plot. As is shown, the data show that the total rate constant has only a very modest temperature dependence, varying by only a factor of two over the range of temperatures. This small range in rate constants is the primary reason for the large apparent scatter in Figure 3. A small but definitely negative activation energy is observed. This is typical of additionelimination or radical-radical reactions rather than direct abstraction reactions, and is in contrast to the positive activation energy previously reported for the $\mathrm{CN}+\mathrm{CH}_{3} \mathrm{Cl}$ reaction [32], suggesting that a different mechanism may dominate. An Arrhenius fit to the data provides the following expression: 


$$
\mathrm{k}_{1}(\mathrm{~T})=(2.20 \pm 0.6) \times 10^{-12} \exp (453 \pm 98 / \mathrm{T}) \mathrm{cm}^{3} \text { molecule }^{-1} \mathrm{~s}^{-1}
$$

where the error bars represent one standard deviation. This leads to an activation energy of $\mathrm{E}_{\mathrm{a}}=-3.76 \pm 0.8 \mathrm{~kJ} \mathrm{~mol}^{-1}$. At $298 \mathrm{~K}$, the rate constant is $\mathrm{k}_{1}=(1.10 \pm 0.1) \times 10^{-11}$ $\mathrm{cm}^{3}$ molecule $\mathrm{e}^{-1} \mathrm{~s}^{-1}$.

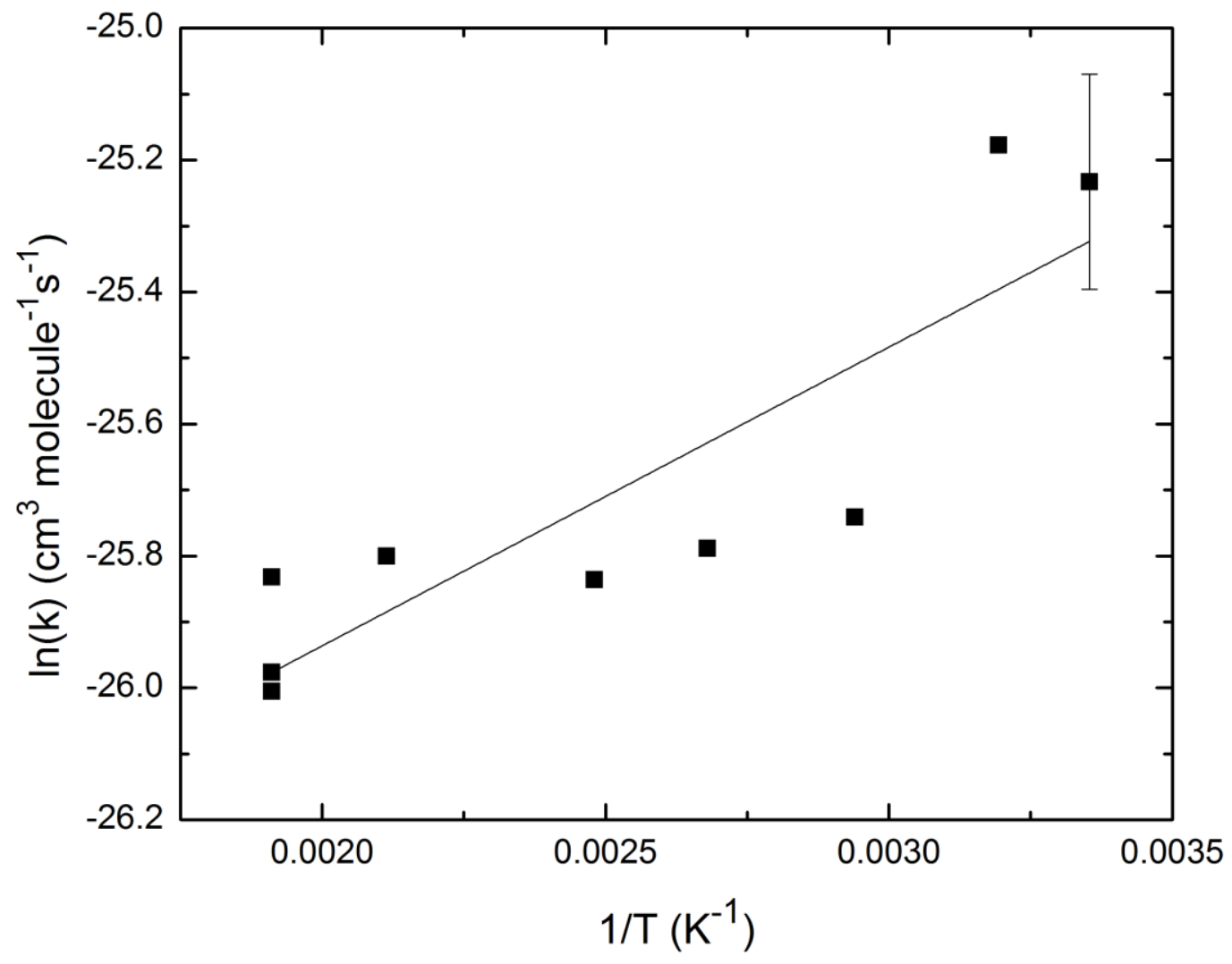

Figure 3: Arrhenius Plot of $\mathrm{ln} \mathrm{k}$ (with $\mathrm{k}$ in $\mathrm{cm}^{3}$ molecule $\mathrm{s}^{-1}$ ) vs. 1/T, for the $\mathrm{CN}+\mathrm{CH}_{3} \mathrm{Br}$ reaction. Error bar represents one standard deviation. 


\subsection{Product Yields}

Infrared diode laser absorption spectroscopy was used to detect $\mathrm{HCN}$ products of the reactions of $\mathrm{CN}$ with $\mathrm{CH}_{3} \mathrm{Br}$. The $\mathrm{CN}+\mathrm{C}_{2} \mathrm{H}_{6}$ reaction, which is expected to produce $\mathrm{HCN}$ in unity yield, was used as a reference reaction. Figure 4 shows typical transient signals. The peak amplitudes of these signals were converted into absolute number densities using linestrengths from the HITRAN database [35]. For the $P(19)$ line at $3251.822 \mathrm{~cm}^{-1}$, the linestrength is $S_{v j}=$ $8.31 \times 10^{-20} \mathrm{~cm}^{-}$molecule-1. Figure 5 shows the resulting $\mathrm{HCN}$ yield as a function of $\mathrm{CH}_{3} \mathrm{Br}$ and $\mathrm{C}_{2} \mathrm{H}_{6}$ pressures. As shown, the $\mathrm{HCN}$ yield increases with increasing reagent $\left(\mathrm{CH}_{3} \mathrm{Br}\right.$ or $\left.\mathrm{C}_{2} \mathrm{H}_{6}\right)$ pressure up to a limiting value at which all of the photolytically produced $\mathrm{CN}$ radicals have reacted with the reagent. At low reagent pressures, competing $\mathrm{CN}$ removal processes such as self reaction, diffusional decay, and reaction with trace oxygen result in lower HCN product yields. The key result of this experiment is that it demonstrates that the $\mathrm{HCN}$ yield of the $\mathrm{CN}+\mathrm{CH}_{3} \mathrm{Br}$ is much lower than that of the $\mathrm{CN}+\mathrm{C}_{2} \mathrm{H}_{6}$ reference reaction (which is assumed to produce $\mathrm{HCN}$ in unity yield). By comparing yields of $\mathrm{HCN}$ at pressures of $\mathrm{CH}_{3} \mathrm{Br}$ or $\mathrm{C}_{2} \mathrm{H}_{6}$ of 1.0 Torr or greater, we estimate a branching fraction of only $0.12 \pm 0.02$ for channel (1a). This is in qualitative agreement with ab initio calculations [33] that suggested the possibility of alternate product channels such as (1b), (1c), or (1d). Most HCN yield experiments were performed at $298 \mathrm{~K}$, but we did perform one experiment at an elevated temperature $(473 \mathrm{~K})$, obtaining identical results as those at $298 \mathrm{~K}$.

Note that in the above discussion, the assignment of unity yield for HCN production in the $\mathrm{CN}+\mathrm{C}_{2} \mathrm{H}_{6}$ reference reaction is an assumption, and has not been experimentally proven to our knowledge. We can, however, compare the $\mathrm{HCN}$ yields in this reaction to a rough estimate of the initial number of $\mathrm{CN}$ radicals created in our experiment, based on a previously measured 266-nm absorption coefficient of the ICN precursor ( 0.009 $\mathrm{cm}^{-1}$ Torr $^{-1}$, base e) [34], assuming a unity quantum yield for $\mathrm{CN}$ production from ICN photolysis, and the measured pulse energies in this experiment. We typically find that the $\mathrm{HCN}$ yield is $\sim 70 \%$ of the estimated $[\mathrm{CN}]_{0}$. 
Although the uncertainties in this estimate are substantial, it does demonstrate that $\mathrm{HCN}$ is at least the dominant channel of the reference reaction.

One issue that could affect the product yield results is the possibility that the reaction produces $\mathrm{HCN}$ with nascent vibrational or rotational excitation. The linestrengths in the HITRAN database that we use to convert transient signal amplitudes assumes a room temperature Boltzmann distribution of quantum states. Any rotational relaxation is expected to be quickly relaxed by collisions, and the use of SF6 buffer gas probably causes vibrational excitation to be also relaxed, but we are not aware of literature data that verifies this. Therefore, in order to test whether this is an issue, we performed some experiments in which we measured the static HCN absorption after firing multiple photolysis laser shots (typically 50), using our standard reaction mixtures. This approach is generally less accurate than using transient signals, because of possible secondary chemistry due to buildup of products, any secondary chemistry slower than the timescale of the transient signals, and possible wall reactions. Nevertheless, this approach allows any vibrational excitation to relax to a Boltzmann distribution. We find that the ratio of static $\mathrm{HCN}$ produced by 50 photolysis shots upon an $\mathrm{ICN} / \mathrm{CH}_{3} \mathrm{Br}_{2} \mathrm{SF}_{6}$ mixture is only $13 \%$ of that produced by an equal number of photolysis shots on an $\mathrm{ICN}_{2} \mathrm{C}_{2} \mathrm{H}_{6} / \mathrm{SF}_{6}$ mixture, in almost perfect agreement with the transient signal results. Either the $\mathrm{HCN}$ is produced vibrationally cold, or the relaxation rates are sufficient high to relax any vibrationally excited $\mathrm{HCN}$ on the timescale $(\sim 50 \mu \mathrm{sec})$ of the transient signals.

Products from channels (1b), (1c), and (1d) are in principle detectable, although with very low sensitivity. Using published spectroscopic data [41] we were able to locate several $\mathrm{BrCN}$ lines at $2202.523,2203.025$, and $2202.965 \mathrm{~cm}^{-1}$. No transient signals at these locations were detected upon photolysis of $\mathrm{ICN} / \mathrm{SF}_{6} / \mathrm{CH}_{3} \mathrm{Br}$ mixtures, but small static absorption lines at these wavelengths were observed to slowly appear over the course of $\sim 100$ photolysis laser pulses. Observation of these same spectral lines using neat BrCN samples shows that these are extremely weak absorption lines, so the absence of transient signals does not allow us to draw any quantitative conclusions regarding the yield of $\mathrm{BrCN}$. Nevertheless, it appears that $\mathrm{BrCN}$ is a product of reaction (1), possibly the major product. Similarly, $\mathrm{CH}_{3} \mathrm{CN}$ products from channel (1c) can be detected near $2290 \mathrm{~cm}^{-1}$. Again, spectral lines in this wavelength region are very weak based on observations using neat $\mathrm{CH}_{3} \mathrm{CN}$ samples. No transient signals were observed, and 
only very small static absorption lines were observed over several hundred photolysis laser pulses. Based on this observation, we believe that channel (1c) is at most a minor product channel. Lastly, we searched for $\mathrm{HBr}$ product molecules at $2649.092 \mathrm{~cm}^{-1}$. Again, no transient signals were observed. Furthermore, no static absorption lines were observed even after several hundred photolysis laser pulses. For this molecule, HITRAN linestrengths are available [37]; the line used has a linestrength of $4.46 \times 10^{-20} \mathrm{~cm}$ molecule ${ }^{-1}$. Based on this, we estimate an upper limit of $\sim 0.01$ for the branching fraction of channel (1b).

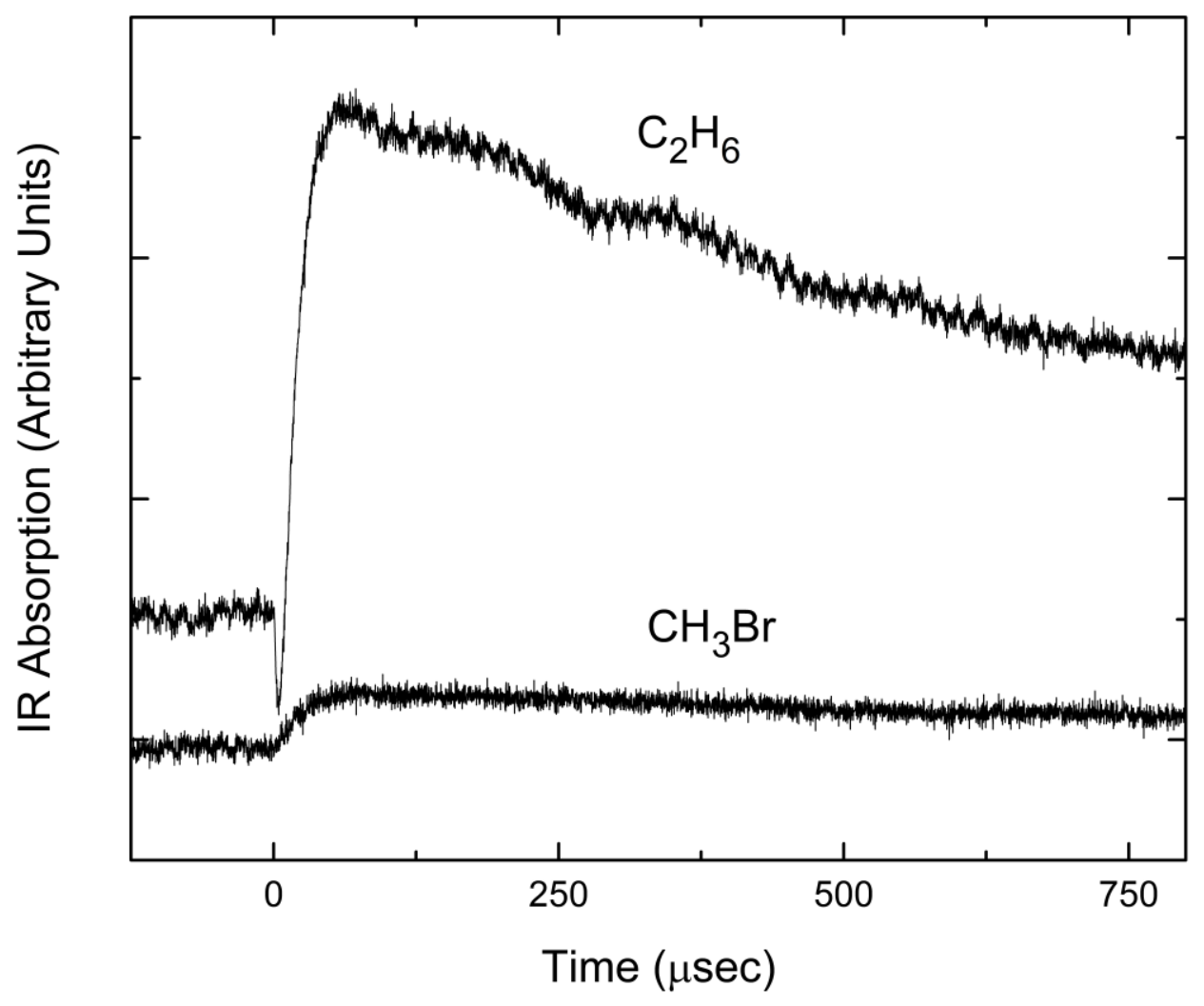

Figure 4: Transient infrared absorption signals for $\mathrm{HCN}$ product detection from the $\mathrm{CN}+\mathrm{CH}_{3} \mathrm{Br}$ and $\mathrm{CN}+\mathrm{C}_{2} \mathrm{H}_{6}$ reactions at $298 \mathrm{~K}$. $\mathrm{P}(\mathrm{ICN})=0.10$ Torr, $\mathrm{P}\left(\mathrm{CH}_{3} \mathrm{Br}\right)=1.6$ Torr (lower trace only), $\mathrm{P}\left(\mathrm{C}_{2} \mathrm{H}_{6}\right)=1.6$ Torr (upper trace only), $\mathrm{P}\left(\mathrm{SF}_{6}\right)=0.5$ Torr. 


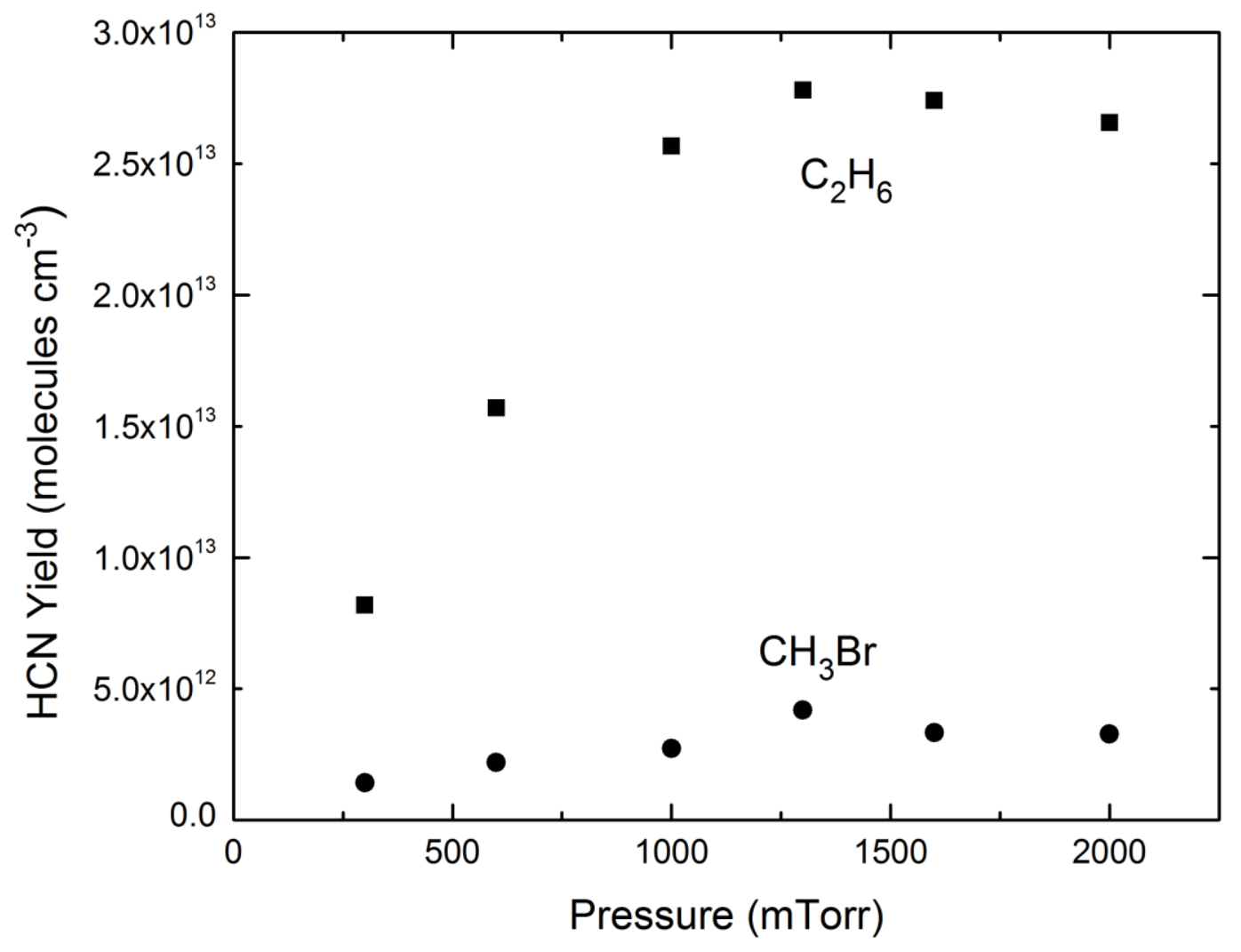

Figure 5: $\mathrm{HCN}$ yield as a function of $\mathrm{CH}_{3} \mathrm{Br}$ (solid circles) and $\mathrm{C}_{2} \mathrm{H}_{6}$ (solid squares) reagent pressure. All data obtained at $298 \mathrm{~K} . \mathrm{P}(\mathrm{ICN})=0.1$ Torr, $\mathrm{P}\left(\mathrm{SF}_{6}\right)=0.5$ Torr, $\mathrm{P}\left(\mathrm{CH}_{3} \mathrm{Br}\right)=$ variable (lower trace only), $\mathrm{P}\left(\mathrm{C}_{2} \mathrm{H}_{6}\right)=$ variable (upper trace only). 


\subsection{Discussion}

The primary experimental result in this study is the finding that hydrogen abstraction to form $\mathrm{HCN}+\mathrm{CH}_{2} \mathrm{Br}$, channel (1a), is only a minor product channel, with an estimated branching fraction of $0.12 \pm 0.02$. It is useful to compare this result with recent ab initio calculations [33]. In those calculations, Farahani et al predicted a free energy barrier of $4.9 \mathrm{kcal} / \mathrm{mol}$ and $5.0 \mathrm{kcal} / \mathrm{mol}$ for hydrogen abstraction and bromine abstraction, respectively. They also used conventional transition state theory to predict rate constants of $3.3 \times 10^{-12} \mathrm{~cm}^{3}$ molecule ${ }^{-1} \mathrm{~s}^{-1}$, and $2.25 \times$ $10^{-12} \mathrm{~cm}^{3}$ molecule ${ }^{-1} \mathrm{~s}^{-1}$ for the hydrogen abstraction and bromine abstraction channels, respectively, at $298 \mathrm{~K}$; this predicts a total rate constant of $5.55 \times 10^{-12} \mathrm{~cm}^{3}$ molecule ${ }^{-1} \mathrm{~s}^{-1}$, somewhat smaller than our experimental value of $1.10 \times 10^{-11} \mathrm{~cm}^{3}$ molecule $\mathrm{s}^{-1}$, but still reasonable agreement. Their rate constants predict a branching fraction of 0.6 into the hydrogen abstraction channel, which is considerably larger than our value of 0.12 . Furthermore, their barrier heights would imply a positive activation energy, in contrast to the experimental observations. It appears, based on the experimental data, that the ab initio calculations probably overestimated the barrier height for the bromine abstraction channel. Nevertheless, the calculations and experiments are in qualitative agreement that hydrogen abstraction is not the only accessible channel, and therefore may not dominate the reaction, in contrast to reactions of $\mathrm{CN}$ with saturated hydrocarbons

It is also useful to compare our results to previous results for the $\mathrm{CN}+\mathrm{CH}_{3} \mathrm{Cl}$ reaction [32]. In that study, a slightly slower rate constant of $9.03 \times 10^{-12} \mathrm{~cm}^{3}$ molecule-1 $\mathrm{s}^{-1}$ at $298 \mathrm{~K}$ was observed, and positive $10.1 \mathrm{~kJ} / \mathrm{mol}$ activation energy was observed. Although direct $\mathrm{HCN}$ detection was not performed in those experiments, the kinetic data was consistent with hydrogen abstraction to form $\mathrm{HCN}$ as a major, possibly dominant channel, in agreement with recent calculations [33]. We therefore conclude that $\mathrm{CH}_{3} \mathrm{Cl}$ and $\mathrm{CH}_{3} \mathrm{Br}$ react with $\mathrm{CN}$ by different mechanisms.

\section{Conclusions}


The reaction of $\mathrm{CN}$ with $\mathrm{CH}_{3} \mathrm{Br}$ is moderately fast at room temperature with a total rate constant of $(1.10 \pm 0.1) \times 10^{-11} \mathrm{~cm}^{3}$ molecule $\mathrm{s}^{-1} \mathrm{~s}^{-1}$. This reaction displays a small negative activation energy, suggesting, in agreement with theoretical predictions, that direct hydrogen abstraction to form $\mathrm{HCN}$ is not the dominant channel. Direct detection and quantification of the $\mathrm{HCN}$ yield verifies this result, indicating that $\mathrm{HCN}$ formation accounts for only $12 \%$ of the reaction rate. The dominant channel was not quantified, but is most likely $\mathrm{BrCN}+\mathrm{CH}_{3}$.

\section{Acknowledgement}

This work was supported by the Division of Chemical Sciences, Office of Basic Energy Sciences of the Department of Energy, Grant DE-FG03-96ER14645.

\section{References}

[1] D.L. Baulch, C.J. Cobos, R.A. Cox, P. Frank, G. Hayman, Th. Just, J.A. Kerr, T. Murrells, M.J. Pilling, J. Troe, R.W. Walker, and J. Warnatz, J. Phys. Chem. Ref. Data 23, (1994) 847.

[2] C. Anastasi and D.U. Hancock, J. Chem. Soc., Faraday Trans. 2, 84, (1988) 9.

[3] D.A. Lichtin and M.C. Lin, Chem. Phys. 96, (1985) 473.

[4] R.J. Balla and K.H. Castleton, J. Phys. Chem. 95, (1991) 2344.

[5] I.R. Sims, J.-L. Queffelec, D. Travers, B.R. Row, L.B. Herbert, J. Karthauser, I.W.M. Smith, Chem. Phys. Lett. 211, (1993) 461.

[6] L. Herbert I.W.M Smith, R.D. Spencer-Smith, Int. J. Chem. Kinet. 24 (1992) 791.

[7] D.L. Yang, T. Yu, M.C. Lin, C.F. Melius, Chem. Phys. 177 (1993) 271.

[8] B. Atakan, J. Wolfrum, Chem. Phys. Lett. 186 (1991) 547.

[9] L.R. Copeland, F. Mohammed, M. Zahedi, D.H. Volman, W.M. Jackson, J. Chem. Phys. 96 (1992) 5817.

[10] W.P. Hess, J.L. Durant, Jr., F.P. Tully, J. Phys. Chem. 93 (1989) 6402.

[11] G. Saidani, Y. Kalugina, A. Gardez, L. Biennier, R. Georges, F. Lique, J. Chem. Phys. 138 (2013) 124308.

[12] M.T. Butterfield, T. Yu, M.C. Lin, Chem. Phys. 169 (1993) 129.

[13] A. Gardez, G. Saidani, L. Biennier, R. Georges, E. Hugo, V. Chandrasekaran, V. Roussel, B. Rowe, K. Reddy, E. Arunan, Int. J. Chem. Kinet. 44 (2012) 753.

[14] H. Reisler, M. Mangir, and C. Wittig, Chem. Phys. 47, (1980) 49.

[15] M.Y. Louge and R.K. Hanson, Int. J. Chem. Kinet. 16, (1984) 231.

[16] I.R. Sims, J.-L. Queffelec, A. Defrance, C. Rebrion-Rowe, D. Travers, P. Bocherel, B.R.

Rowe, and I.W.M. Smith, J. Chem. Phys. 100, (1994) 4229. 
[17] R.C. Jensen, D.B. Walton, and R.D. Coombe, Ber. Bunsen-Ges. Phys. Chem. 169, (1990) 441.

[18] J.L. Durant, Jr. and F.P. Tully, Chem. Phys. Lett. 154, (1989) 568.

[19] B. Atakan, A. Jacobs, M. Wahl, R. Weller, and J. Wolfrum, Chem. Phys. Lett. 154, (1989) 449.

[20] M. Burmeister, S.K. Gulati, K. Natarajan, K. Theilen, E. Mozzhukin, and P. Roth, Symp. (Int.) Combust. (Proc.) 22, (1989) 1083.

[21] I.R. Sims and I.W.M. Smith, J. Chem. Soc. Faraday Trans. 89 (1993) 1.

[22] Y.Y. You and N.S. Wang, J. Chin. Chem. Soc. (Taipei) 40, (1993) 337.

[23] W. Tsang, J. Phys. Chem. Ref. Data 21 (1992) 753.

[24] K.T. Rim and J.F. Hershberger, J. Phys. Chem. 103 (1999) 3721.

[25] W. Feng and J.F. Hershberger, J. Phys. Chem. 113 (2009) 3523.

[26] J. Park and J.F. Hershberger, J. Chem. Phys. 99 (1993) 3488.

[27] J. Park and J.F. Hershberger, Chem. Phys. Lett. 295, (1998) 89.

[28] W. Feng and J. F. Hershberger, J. Phys. Chem. A. 115, (2011) 286.

[29] W. Feng and J.F. Hershberger, J. Phys. Chem. A 110, (2006) 12184.

[30] W. Feng and J.F. Hershberger, J. Phys. Chem. A 116, (2012) 10285.

[31] E. Janssen and J.F. Hershberger, Chem. Phys. Lett. 625 (2015) 26.

[32] V. Samant and J.F. Hershberger, Chem. Phys. Lett 460 (2008) 64.

[33] P. Farahani, S. Maeda, J. S. Francisco, and M. Lundberg, ChemPhysChem 16 (2015)181.

[34] W.F. Cooper, J. Park, and J.F. Hershberger, J. Phys. Chem. 97 (1993) 3283.

[35] H. Okabe, Photochemistry of Small Molecules, Wiley-Interscience (1978).

[36] W.F. Cooper, J.F. Hershberger, J. Phys. Chem. 96 (1992) 771.

[37] L. S. Rothman, et al. J. Quant. Spectrosc. Radiat. Transfer. 48 (1992) 469.

[38] A. Maki, W. Quapp, S. Klee, G.C. Mellau, and S. Albert, J. Molec. Spectrosc. 10 (1996) 323.

[39] A.G. Maki, G. C. Mellau, S. Klee, M. Winneisser and W. Quapp, J. Molec. Spectrosc. 202 (2000) 67.

[40] D. Cerny, R. Bacis, G. Guelachvili, F. J. Rousx., Mol. Spectrosc. 73 (1978) 154.

[41] F. Tamassia, C. Degli Esposti, L. Dore, G. Cazzoli, J. Molec. Specrosc. 174 (1995) 59. 


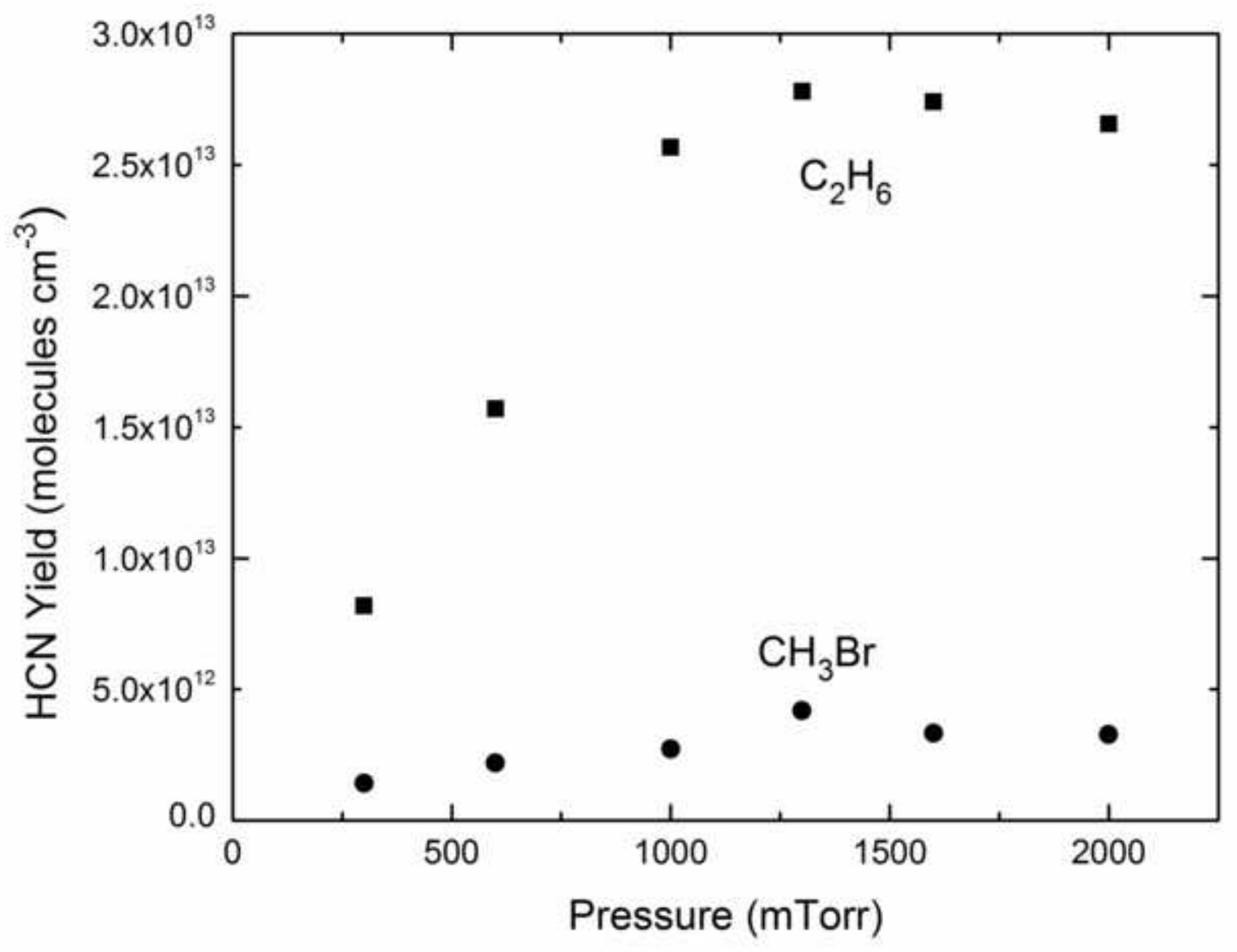

